\title{
Empatian kulttuurinen politiikka
}

\author{
Monilajisen empatian idea avaa mahdollisuuksia \\ kyseenalaistaa oletuksia, jotka hierarkisoivat \\ elämänmuotoja. Onko empatia itsessään kuitenkaan \\ ratkaisu kaikissa konteksteissa ja kaikkina aikoina \\ vaarallisiin hierarkioihin, joiden keskellä elämme?
}

"KASVATUS MONILAJISEEN EMPATIAAN" -artikkeli pureutuu valtasuhteisiin, jotka tulevat ilmeisiksi liha- ja kasvisruokaan liitetyissä tunteissa. Siinä missä tapettua, kuollutta eläintä on mahdollista lähestyä maukkaana ja nautinnollista elämystä tarjoavana lihapalana, kasvisruoka voi herättää jopa huolia lasten ja koko kansakunnan turvallisuudesta, niin kuin Mikko Rosenberg huomioi.

Kulttuurissamme on lukuisia keinoja häivyttää lihansyöntiin liittyviä valtasuhteita, ja yksi keskeinen lienee se, kuinka 'liha' muuttaa eläimen ruoaksi. Jos haluamme syödä eläimiä, emme yleensä assosioi haluamme 'eläimiin' vaan lihaan.

Rosenberg käyttää termiä 'ruokahalu' kuvaamaan kulttuurisesti määrittyneitä haluja, jotka kohdistuvat tietynlaiseen ruoaksi assosioitavaan aineeseen. Ruokahalu lihaan on Rosenbergin mukaan yksilöllisesti koettu, mutta sitä ei voi tiivistää pelkästään yksilön omiin henkilökohtaisiin mieltymyksiin, vaan se ammentaa laajemmista yhteiskunnallisista valtasuhteista.

Rosenberg purkaa lihansyöntiin liittyviä tunnereaktioita ja tuo esiin, kuinka lihansyönti sen nykyisenkaltaisissa muodoissa kytkeytyy paitsi kapitalismiin ja lajismiin myös - vähemmän ilmeisesti - käsityksiin sukupuolesta ja länsimaalaisuudesta. Lihansyömishalut eivät näyttäydy artikkelissa yhdentekevinä jokaisen omina valintoina vaan kulttuurisen merkityksenannon seurauksina. Rosenberg laittaa ilmoille kysymyksen, mitä voisi tapahtua näille arkisille haluille ja elämänmuodoillemme laajemmin, jos vallitseva kulttuurinen tunne olisi monilajinen empatia.

\section{VAIHTOEHTOISET TUNTEET}

Empatiaa kokeva on avoin vaikutuksille. Ajattelen, että reaktiona empatia on reflektiivistä itsen ja tois- 


\section{Myös TUNNE VOI}

\section{OLLA OBJEKTI,}

\section{JONKA HER ÄTT $\ddot{M} \ddot{A} T$}

\section{MIELLEYHTYMÄT OVAT}

HISTORIALLISIA.

ten välisen tilanteen tunteikasta punnitsemista. Siinä voi nähdä sekä kognitiivisia että emotionaalisia piirteitä. Käsitykseni mukaan Rosenbergille monilajinen empatia tarkoittaa kulttuurisissa tarinoissa välittyvää suhdetta ympäristöön, lajeihin ympärillämme ja sisällämme sellaisella tavalla, jossa tuota suhdetta ei määrittele kilpailu vaan arvostava vuorovaikutus.

Monilajisen empatian subjekti ei ole ainoastaan ihminen, vaan kirjoittaja tuo esiin, kuinka jotkut empatiasta kirjoittavat tutkijat ovat liittäneet kyseisen tunteen myös ei-inhimillisten lajien toimintaan. Monilajisen empatian eri muotojen esiin tuominen avaa kulttuurista arkistoa tunteisiin (ks. Cvetkovich 2003) - potentiaalisesti artikuloiden uudelleen yhteiskunnallisia valtasuhteita.

On tärkeää huomata, että kulttuurintutkimuksen teoriaa on jo vuosikymmenten ajan kehystänyt idea vaihtoehtoisista tunteista, jotka asettuvat vastahankaan vallitsevan ideologian kanssa. Kulttuurintutkimuksen pioneeri Stuart Hall teoretisoi vuonna 1986 ilmestyneessä tekstissään "The Problem of Ideology Marxism without Guarantees", kuinka kapitalismi olettaa tietynlaiset tunnerakenteet. Hall (1996 [1986]) mainitsee itsen ja toisen välistä hyväntahtoisuutta korostavat tunteet porvarillisen talousteorian normeihin sopimattomina: markkinoiden kontekstissa ihmisen oletetaan toimivan itsekkäästi eikä hyväntahtoisuuden tai rakkauden ohjaamana.

Myös Raymond Williams, toinen brittiläisen kulttuurintutkimuksen uranuurtaja, oli kiinnostunut nimenomaan tunteiden ja yhteiskunnan välisistä suhteista. Williams (1979, 1983 [1958], 2009 [1977]) tutki tunteita painottaen yhtäältä tiettyjen tunteiden järjestelmällistä piilevyyttä yhteiskunnassa tiettyinä aikoina ja toisaalta heterogeenisiä ja keskenään konfliktissa olevia eri ihmisryhmien välisiä tunnekokemuksia. Näistä näkökulmista tunteet avautuvat moninaisina reaktioina maailmaan.

Vaikka tietynlaiset tunteet ja affektit voidaan asettaa yhteiskunnassa etusijalle, tunteita yhteiskuntatieteellisestä näkökulmasta katsova tutkimus voisi kysyä, mitä tietyillä tunteilla tehdään yhteiskunnallisesti tiettyinä historiallisina hetkinä. Tähän näkökulmaan voisi kuulua empatian asettaminen tutkimuskohteeksi, jolla on monimuotoinen historia ja nykyisyys.

\section{EMPATIA KULTTUURISENA TUNTEENA}

Rosenbergin idea sellaisten lähestymistapojen vaalimisesta, joissa kaikki elämänmuodot näyttäytyisivät arvokkaina, on äärimmäisen tärkeä. Vaikka monilajisen empatian idea avaa mahdollisuuksia kyseenalaistaa oletuksia, jotka hierarkisoivat elämänmuotoja, onko kuitenkaan empatia itsessään ratkaisu kaikissa konteksteissa ja kaikkina aikoina vaarallisiin hierarkioihin, joiden keskellä elämme? Minusta on tarpeellista erottaa toisistaan empatia kulttuurisena tunteena ja subjektin sisäisenä kokemuksena, joka on toki aina ulkoisen maailman muokkaamaa.

Empatiaa kulttuurisena tunteena voidaan pitää historiallisesti muodostuneena ideana tietyistä tunnekokemuksista. Sitä voidaan lähteä jäljittämään metodologialla, joka seuraa empatian idean moninaisia muotoja erilaisissa yhteyksissä. Tunteiden kulttuuripolitiikan tutkija Sara Ahmed $(2014,214)$ on yhdistänyt osuvasti filosofi Michel Foucault'n $(1977,139)$ kuvauksen genealogisesta otteesta näkökulmana, joka jäljittää sitä, minkä ”tunnemme olevan ilman historiaa" kulttuurintutkimukselliseen tunteiden analyysiin. Ahmedin mukaan objektien ja niihin assosioitavien voimakkaiden, jopa autonomisilta vaikuttavien, tunnereaktioiden välinen yhteys voidaan asettaa kyseenalaiseksi, sillä tällaiset tunnereaktiot ovat historian muokkaamia. Vaikka me voisimme tuntea tiettyjen tunnereaktioiden "olevan ilman historiaa", Ahmed osoittaa esimerkiksi, kuinka tiettyihin kehoihin liimaantunut pelottavuus on seurausta yhteiskunnallisesta toiminnasta. Toisaalta myös tunne voi olla objekti, jonka herättämät mielleyhtymät ovat historiallisia. 
Sukupuolentutkija Kyla Schuller (2018) on jäljittänyt, kuinka sentimentaalisuus alettiin 1900-luvun puoliväliin tultaessa mieltää negatiivisesti, vaikka vielä 1800-luvulla tunteikas vaikutuksille alttius nähtiin edistyksellisenä ominaisuutena. 1800-luvun Yhdysvalloissa Jean-Baptiste Lamarckin (1744-1829) mukaan nimetty lamarckismi mahdollisti monenlaisia yhteiskunnallisia ideoita. Sen kenties parhaiten tunnettu esimerkki on kirahvien pitkä kaula, joka Lamarckin teorian mukaan johtuisi lehtien kurottelusta puista. Lamarckismi korosti siis organismin elämänaikaisen toiminnan vaikutusten periytyvyyttä, ja 1900-luvulle tultaessa teoria alkoi näyttäytyä epätieteellisenä. Schullerin mukaan 1800-luvulla se mahdollisti kiinnostavasti valkoisten naisten emansipaatiota ideoilla naiskehon muokkautumiskykyisyydestä. Samalla lamarckistisia ideoita käytettiin eugeniikkaan sitoutuneissa pyrkimyksissä parantaa rodun ominaisuuksia.

Sentimentaalisuus näyttäytyi lamarckismin vaikutuksesta 1800-luvun evoluutiotieteen keskusteluissa kykynä muokata hienovaraisesti itseä. Sivistyneiksi assosioidut ihmisryhmät esitettiin kehittyneinä tunteiden säätelyssä; heidän sentimentaalisuutensa mahdollisti kulttuurin kehittymisen. Idea kulttuurin kehittymisestä on puolestaan ollut oleellinen rasistisissa hierarkioissa 1800-luvulta alkaen. Sentimentaalisuus toimi siis rodullistavana ideana. Se sitoutui ihmisryhmien hierarkisointiin sen mukaan, mitkä ryhmät voivat parhaiten ilmentää sivistystä tunteisiin liittyvien ominaisuuksiensa kautta. Kuitenkin geneettistä determinismiä korostavien ideoiden voimistuessa sentimentaalisuudesta tuli miltei haukkumasana turhalle tunteikkuudelle, jolla ei olisi kykyä muuttaa biologisia lainalaisuuksia. (Mt.)

Schuller osoittaa, miten tiettyihin tunteisiin liitetyt mielleyhtymät ovat historiallisia ja muuttuvia. Hän ei sano, että meidän pitäisi ottaa mallia muokkautumiskyvyn ideaa vaalineista aatteista. Sen sijaan tulisi tutkia kriittisesti sekä determinismiin että muokkautumiskyvyn ideaan sitoutuneita ajattelutapoja. Meidän ei myöskään tarvitse asettua sentimentaalisuutta vastaan, vaan sen sijaan tutkia sentimentaalisuuden monimuotoista toimintaa yhteiskunnassa. Samankaltainen lähestymistapa em- patiaan voisi mahdollistaa empatiakyvyn kulttuurisen toiminnan tarkkaavaisen analyysin.

Kulttuurintutkija Carolyn Pedwell (2012) on varoittanut luottamasta tunteiden - erityisesti empatian - kykyyn uudelleen järjestää epätasa-arvoisia yhteiskunnallisia tilanteita. Jos yhteiskunnallista eriarvoisuutta puretaan kehittämällä tunnetaitoja, saatetaan Pedwellin (2012) mukaan yksilöllistää rakenteellisia ongelmia. Suomalaisen kasvatustieteen kontekstissa samantyyppisiin johtopäätöksiin on tullut Kristiina Brunila (2012).

\section{EMPATIA KYKYNÄ JA VALTASUHTEIDEN VERKOSTOSSA}

Empatian kehittäminen keinona edistää oikeudenmukaisempaa maailmaa herättää kysymyksiä, keille empatia avautuu ominaisemmaksi lähestymistavaksi ja toisaalta keihin empatia ulottuu. Kuinka taloudelliset ja yhteiskunnalliset etuoikeudet määrittävät sitä, keistä voi tulla empatian subjekteja ja objekteja (ks. myös Pedwell 2012)? Jos empatiaa lähestytään kykynä, jonka kehittäminen nähdään välttämättömäksi, jotta yhteiskunta voi toimia halutulla tavalla, minkälaisia biopoliittisia kysymyksiä on tarpeen silloin tutkia tarkkaavaisesti?

On myös tärkeää ajatella empaattisuutta affektiivisena tilana, joka voi paitsi mahdollistaa arvostavia kohtaamisia myös uuvuttaa sen kokijan. Voikin olla aiheellista kysyä, minkälaisia vaikutuksia itsessä ja ympäristössä empaattisuus voi saada aikaan ja kuinka empatian vaikutukset itseen ja muihin kytkeytyvät intersektionaalisiin hierarkioihin. Monilajinen empatia voisi lähestyä myös kysymyksiä, jotka altistavat empatian ideana ja kokemuksena sen ongelmallisten ja jopa vahingollisten muotojen tarkastelulle. Näin olisi mahdollista päästä empatian kulttuurisen politiikan (ks. Ahmed 2014) ulottuvuuksiin.

Jos lähestymme empatiaa kuin sillä ei olisi historiaa, on mahdollista, että sallimme sen nimissä asioita, joita emme muutoin hyväksyisi. Kasvatustiede on kohdistanut kriittisen katseensa kasvatukseen paimenvaltana, jonka vaikutus ulottuu tunteisiin ja sisäiseen maailmaan. Koska empatialla voidaan tehdä politiikkaa, tarvitsemme sen kulttuuristen muoto- 
jen tarkkaa analyysia erityisesti kasvatustieteessä. Samanaikaisesti kasvatustieteellinen tutkimus, joka kyseenalaistaa monilajiset hierarkiat ja empatian rajallisuuden, voi kirjoittaa uusiksi kulttuurisia toiveita kehityksestä ja asettaa keskiöön marginalisoituja tunnerakenteita.

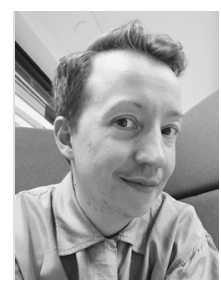

FT

(D) https://orcid.org/0000-00025710-5538

\section{LÄHTEET}

Ahmed, S. (2014). The Cultural Politics of Emotion, Second Edition. Edinburgh: Edinburgh University Press.

Brunila, K. (2012). Tunnekoukussa: syrjäytymisvaarassa olevien nuorten aikuisten koulutus terapeuttisessa eetoksessa. Aikuiskasvatus 32(4), 268-277.

Cvetkovich, A. (2003). An Archive of Feelings. Trauma, Sexuality, and Lesbian Public Cultures. Durham: Duke University Press.

Foucault, M. (1977). Nietzsche, Genealogy, History. Teoksessa Bouchard, D. F. (toim.) Language, CounterMemory, Practice. Selected Essays and Interviews. Ithaca: Cornell University Press, 139-164.

Hall, S. (1996 [1986]). The Problem of Ideology: Marxism without Guarantees. Teoksessa Morley, D \& Chen, K.-H. (toim.) Stuart Hall: Critical Dialogues in Cultural Studies. New York: Routledge, 25-46.

Pedwell, C. (2012). Economies of Empathy: Obama, Neoliberalism, and Social Justice. Environment and Planning D: Society and Space 30(2), 280-297.

Schuller, K. (2018). The Biopolitics of Feeling. Race, Sex, and Science in the Nineteenth Century. Durham: Duke University Press.

Williams, R. (1979). Politics and Letters. Interviews with New Left Review. London: NLB / Verso Editions.

Williams, R. (1983 [1958]). Culture \& Society 17801950. New York: Columbia University Press.

Williams, R. (2009 [1977]). Marxism and Literature. Oxford: Oxford University Press. 